\title{
Laparoscopic detorsion of gangrenous adnexae followed by interval cystectomy: case report and review of the literature
}

\author{
Roziana Ramli*, Halimatun Mansor, Yusmadi Abdullah, \\ Noraini Mulalek, Wan Abu Bakar Yusoff
}

Department of Obstetrics \& Gynaecology, Hospital Sultanah Nur Zahirah, Kuala Terengganu, Malaysia

Received: 28 March 2015

Revised: 02 April 2015

Accepted: 09 May 2015

\author{
*Correspondence: \\ Dr. Roziana Ramli, \\ E-mail: drroziana@yahoo.com
}

Copyright: ( $)$ the author(s), publisher and licensee Medip Academy. This is an open-access article distributed under the terms of the Creative Commons Attribution Non-Commercial License, which permits unrestricted non-commercial use, distribution, and reproduction in any medium, provided the original work is properly cited.

\begin{abstract}
A 15 year old girl presented with a 1-day history of acute abdomen. Abdominal ultrasound revealed a left adnexal cyst measuring $8 \times 7 \mathrm{~cm}$. Laparoscopic examination demonstrated an $8 \mathrm{~cm}$ left gangrenous adnexal torsion. After detorsion of the left adnexae, the left fallopian tube appeared to be viable however the left ovary remained the same. Postoperative period was uneventful and serial ultrasound showed persistence of the cyst. The left ovary appeared to be completely viable through a repeat laparoscopic examination 6 weeks later and interval left cystectomy was performed. A twisted gangrenous adnexae could be managed by adnexal sparing surgery successfully.
\end{abstract}

Keywords: Twisted gangrenous adnexae, Detorsion, Adnexal sparing surgery

\section{INTRODUCTION}

The incidence of adnexal masses in the pediatric and adolescent population is approximately 2.6 per 100000 girls per year. ${ }^{1}$

Ovarian torsion is even rarer. Although rare, management of ovarian torsion in children and young adults is important because it could be associated with failure of fertility preservation and loss of endocrine function. Many surgeons would perform surgical resection for twisted gangrenous adnexae without detorsion.

Current evidence however is in favour of adnexal sparing surgery to preserve ovarian function. Here, we present a young girl with ovarian torsion who was successfully managed with conservative treatment using laparoscopic detorsion and interval cystectomy.

\section{CASE REPORT}

A previously healthy 15 year old schoolgirl was brought to Emergency Department complaining of severe abdominal pain associated with vomiting on the day of admission. Vital signs were stable and she was afebrile. Clinically the abdomen was tender and guarded at suprapubic region. No mass was palpable. Urine analysis for infection and pregnancy were both negative. Transabdominal ultrasound revealed a left adnexal cyst measuring $8 \times 7 \mathrm{~cm}$. Diagnosis of Torsion of the Left Ovarian Cyst was made.

Laparoscopy was performed and intra-operatively the uterus and right adnexae appeared normal. However the left ovarian cyst measuring $8 \mathrm{~cm}$ and the left fallopian tube were twisted 4-fold around the base and both were blue-black in colour (Figures 1, 3). Laparoscopic adnexal detorsion was performed and shortly after, the left 
fallopian tube appeared viable (Figure 2) while the left ovary remained blue-black. The postoperative period was uneventful and the patient was discharged well on the $3^{\text {rd. }}$ day post operation. Ultrasound surveillance showed persistence of left ovarian cyst and tumour markers were all normal. She was readmitted 6 weeks later for interval cystectomy.

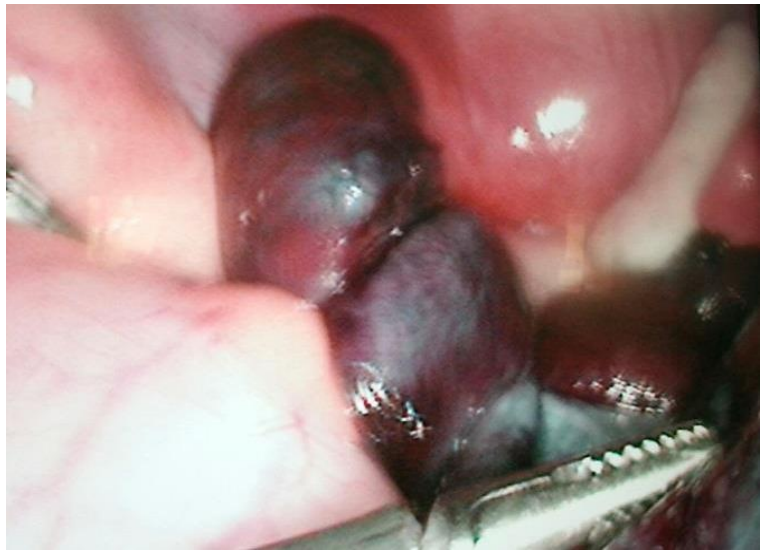

Figure 1: Blue-black right fallopian tube prior to detorsion.

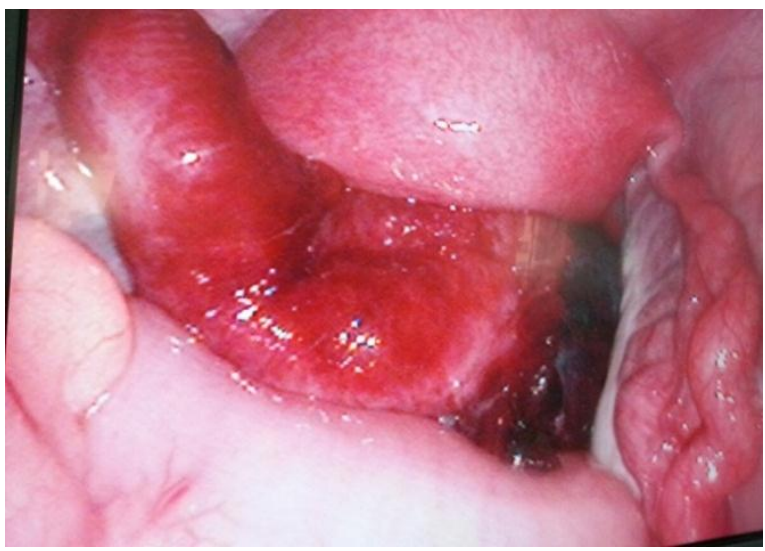

Figure 2: Viable right fallopian tube after detorsion.

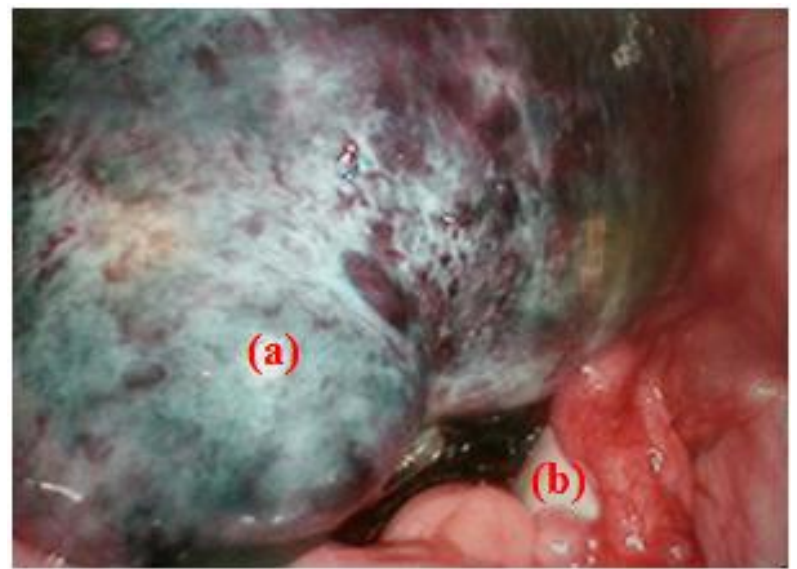

Figure 3: Blue-black right ovarian cyst (a), normal right ovary (b).
During the $2^{\text {nd }}$ laparoscopic procedure, the previously blue-black ovary appeared white and viable. Laparoscopic cystectomy proceeded without difficulty and the left ovary was salvaged (Figures 4, 5, 6). The patient was discharged well few days later. Histopathological diagnosis confirmed benign mature teratoma.

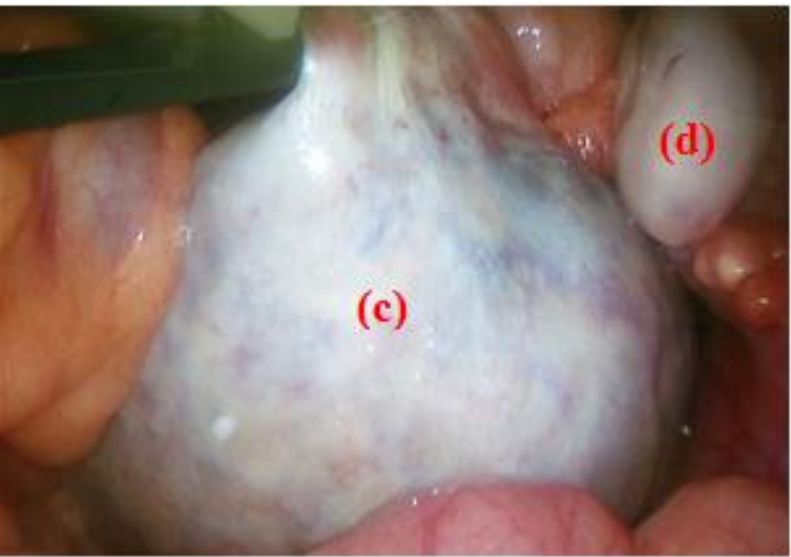

Figure 4: Viable right ovarian cyst (c), normal right ovary (d) 5 weeks after detorsion.

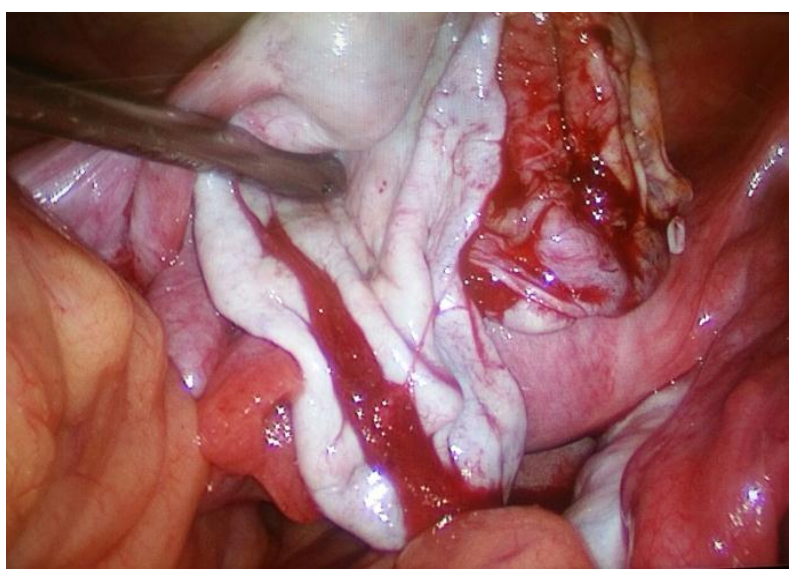

Figure 5: Post left cystectomy showing the left ovary.

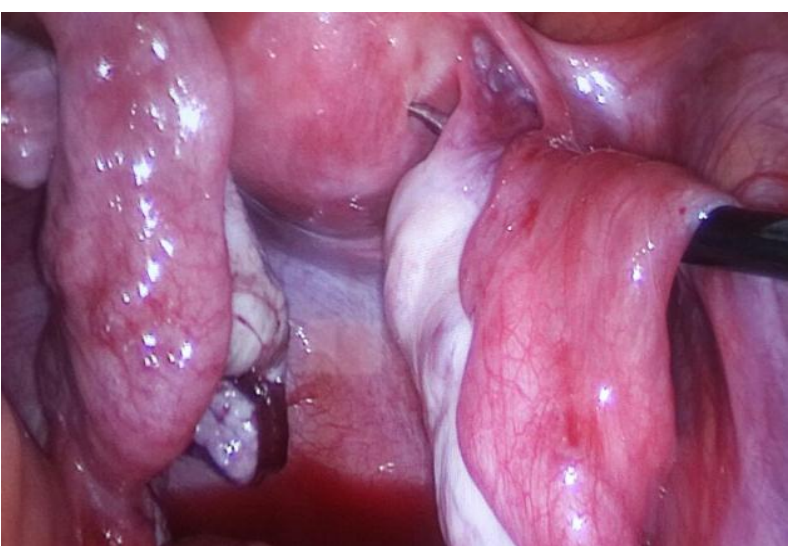

Figure 6: Post left cystectomy showing uterus, both ovaries and fallopian tubes. 


\section{DISCUSSION}

Oophorectomy used to be the standard treatment modality in cases of twisted gangrenous ovary. It is believed that since the ovary is no longer viable, complete resection of the ovary is necessary to prevent infectious morbidity, sepsis and even mortality. Fear of malignancy also influences the decision for complete ovarian resection. Oophorectomy is also traditionally performed without untwisting the twisted pedicle because of the perceived risk of thromboembolism. The fear of unwinding the pedicles of torsed ovary is based on the assumption that this procedure would release ovarian vein thrombus into the systemic circulation.

Over the past decades however, the management of adnexal torsion has moved away from surgical resection. Several studies have reported excellent recovery of ovarian function regardless of the ischaemic/gangrenous appearance of the twisted ovary following conservative approach by detorsion. ${ }^{2-9}$ Interestingly simple detorsion after days of pain suggests there is likely no limit of viability beyond which detorsion should not be attempted. ${ }^{10}$ Successful return of normal ovarian morphology and function have been shown through postoperative ultrasound assessment of folliculogenesis, macroscopic appearance of ovary during subsequent or $2^{\text {nd. }}$ look operation and in some cases successful oocyte recovery during IVF procedure. Most studies quoted more than $90 \%$ of ovarian salvage. . $^{2,711}$

Mc Govern et al. ${ }^{12}$ presented scientific analysis of 981 cases of ovarian torsion described only two cases $(0.02 \%)$ of pulmonary embolism coincidental with ovarian vein thrombosis in a case of adnexal torsion. Interestingly both cases occurred in the adnexal resection group and not in the detorsion group. They concluded that 'detorsion of twisted adnexa does not increase the risk of pulmonary embolism, compared with excision without untwisting'. Wagaman and Williams ${ }^{13}$ in a literature review and Oelsner et al. ${ }^{2}$ found no cases of pulmonary embolism in their study.

Malignancy accounts for roughly $10 \%$ of all ovarian masses. However in torsed ovaries the malignancy rate is markedly reduced. Oltman et al. ${ }^{8}$ reported a $1.8 \%$ malignancy rate in paediatric/adolescent population with ovarian torsion and in adult population, malignancy rate of 1.1 to $2 \%$ has been quoted. ${ }^{14}$ The relative rareness of torsions in malignant case is attributed by inflammatory or tumoral adhesions. ${ }^{15}$ The largest series of torsion in paediatric literature reported all malignancies presented as stage $1 .^{8}$ It is impossible to predict which torsed ovary with underlying malignancy due to oedema, inflammation and anatomical distortion. Persistence of mass following adnexal sparing surgery would dictate an interval procedure with review of tumour markers panel and proper surgery if malignancy is suspected. Further study however is needed to determine whether delaying the resection by weeks would result in tumour progression and thus change the prognosis. ${ }^{8}$
Complication following adnexal sparing surgery is rare and self-limiting. Rody et al. ${ }^{16}$ in his study involving young adults quoted a $4 \%$ rate of having relevant complications following detorsion. Transient postoperative fever and ileus are the most common problems detected , $^{2,11}$ significantly more common following laparotomy compared to laparoscopy. ${ }^{2}$ Bider et al. ${ }^{17}$ and Shalev et al. ${ }^{18}$ observed no increased postoperative infectious morbidity in their series.

When aetiologies of ovarian torsion in children were analyzed, a normal non-tumoral ovary was involved in $0 \%$ to $60.86 \%$ of cases can, $^{2,70,19,20}$ in contrast with adult population(2.2\%). ${ }^{16}$ This inconsistent finding is perhaps due to small sample size in each series and heterogeneity of sample population. Physiological changes at around pubertal age and abnormally long ovarian pedicles have been suggested as an underlying mechanism of ovarian torsion in young patients.

The twisted ischaemic adnexae is oedematous, friable and could easily be traumatized. It is unwise to perform cystectomy in such cases as not only it could be technically difficult, it could also be associated with bleeding, inadvertent removal of normal ovarian tissue and incomplete excision. Post-operative ovarian surveillance would identify persistent ovarian mass which would require a repeat operation 6-8 weeks later after resolution of oedema. In many cases however an interval operation is unnecessary.

Other methods to further increase rate of ovarian salvage have been described. Bivalving is a method proposed by Styer and Laufer ${ }^{21}$ which involves making a linear incision of the affected ovary to decrease ovarian intracapsular pressure to facilitate ovarian reperfusion and recovery. Galinier et al. ${ }^{22}$ however believes that this method appears excessive on an already insulted ovary. Oophoropexy is another method to fix the ovary after detorsion to prevent recurrence, however there is no consensus about this technique nor the preventive pexy on the opposite site. ${ }^{20}$ Nevertheless, it is an interesting method that could be utilized in dealing with non-tumoral adnexal torsion or adnexal torsion in patients with a remaining single ovary.

\section{CONCLUSIONS}

Twisted gangrenous adnexae could elegantly be managed by conservative surgery especially in young patients as illustrated in this case. The perceived risks of infectious morbidity, thromboembolism, malignancy and mortality associated with conservative surgery have been overestimated. Adnexal sparing surgery by detorsion has been proven to be safe and ensures preservation of fertility and endorine function.

Funding: No funding sources

Conflict of interest: None declared

Ethical approval: Not required 


\section{REFERENCES}

1. Skinner MA, Schlatter MG, Heifetz SA, Grosfeld JL. Ovarian neoplasms in children. Arch Surg. 1993;128:849-53.

2. Oelsner G, Cohen SB, Soriano D, Admon D, Mashiach S, Carp H. Minimal surgery for the twisted schaemic adnexa can preserve ovarian function. Hum Reprod. 2003;18:2599-602.

3. Kirkham YA, Lacy JA, Kives S, Allen L. Characteristics and management of adnexal masses in a Canadian pediatric and adolescent population $\mathrm{J}$ Obstet Gynaecol Can. 2011 Sep;33(9):935-43.

4. Ahmet Çelik, Orkan Ergün, Hakan Aldemir, Coşkun Özcan, Geylani Özok, Ata Erdener, et al. Long-term results of conservative management of adnexal torsion in children. J Pediatr Surg. 2005 Apr;40(4):704-8.

5. Breech L, Hillard P. Adnexal torsion in pediatric and adolescent girls. Curr Opin Obstet Gynecol. 2005; 17:483-9.

6. Broach AN, Mansuria SM, Sanfilippo JS. Pediatric and adolescent gynecologic laparoscopy. Clin Obstet Gynecol. 2009;52:380-9.

7. Aziz D, Davis V, Allen L, Langer JC. Ovarian torsion in children: is oophorectomy necessary? J Pediatr Surg. 2004;39:750-3.

8. Oltmann SC, Fischer A, Barber R, Huang R, Hicks $\mathrm{B}$, Garcia ZL, et al. Adnexal torsion in pediatric and adolescent girls. Curr Opin Obstet Gynecol. 2005;17:483-9.

9. Yiu-Tai Li, Lung-ChingKuon, Po-Ning Lee, TsungCheng Kuo. Laparoscopic detorsion of twisted ovary. J Chinese Med Assoc. 2005 Dec;68(12):595-8.

10. Anders J. Ovarian torsion in the pediatric emergency department: making the diagnosis and the importance of advocacy. Clin Ped Emerg Med. 2009;10:31-7.

11. Parelkar SV, Mundada D, Sanghvi BV, Joshi PB, Oak SN, Kapadnis SP, et al. Should the ovary always be conserved in torsion? A tertiary care institute experience. J Pediatr Surg. 2014;49:465-8.

12. McGovern PG, Noah R, Koenigsberg R, Little AB. Adnexal torsion and pulmonary embolism: case- report and review of the literature. Obstet Gynecol Surv. 1999;54(9):601-8.

13. Wagaman R, Williams RS. Conservative therapy for adnexal torsion: case report. J Reprod Med. 1990;35:833-4.

14. Cass DL. Ovarian torsion. Semin Pediatr Surg. 2005;14(2):86.

15. Sommerville M, Grimes DA, Koonings PP, Campbell K. Ovarian neoplasms and the risk of adnexal torsion. Am J Obstet Gynecol. 1991;164:577-8.

16. Rody A, Jackish C, Klockenbusch W, Heinig J, Coenen-Worch V, Schneider HP. The conservative management of adnexal torsion - a case-report and review of the literature. Eur J Obstet Gynecol Reprod Biol. 2002;101:83-6.

17. Bider D, Mashiach S, Dulitzky M, Kokia E, Lipitz S, Ben-Rafael Z. Clinical, surgical and pathologic findings of adnexal torsion in pregnant and nonpregnant women. Surg Gynecol Obstet. 1991;173:363-6.

18. Shalev J, Goldenberg M, Oelsner G, Ben-Rafael Z, Bider D, Blankstein J, et al. Treatment of twisted ischaemic adnexae by simple detorsion. N Engl Med. 1989;24:546.

19. Geimanaite L, Trainavicius K. Ovarian torsion in children: Management and outcomes. J Pediatr Surg. 2013;48:1946-53.

20. Rousseau V, Massicot R, Darwish AA, Sauvat F, Emond S, Thibaud E, et al. Emergency management and conservative surgery of ovarian torsion in children: a report of 40 cases. J Pediatr Adolesc Gynecol. 2008;21:201-6.

21. Styer AK, Laufer MR. Ovarian bivalving after detorsion. Fertil Steril. 2002;77:1053-5.

22. Galinier P, Carfagna L, Delsol M, Ballouhey Q, Lemasson F, Le Mandat A, et al. Ovarian torsion. Management and ovarian prognosis: a report of 45 cases. J Pediatr Surg. 2009;44:1759-65.

DOI: $10.18203 / 2320-1770 . i j r \operatorname{cog} 20150123$

Cite this article as: Ramli R, Mansor H, Abdullah Y, Mulalek N, Yusoff WAB. Laparoscopic detorsion of gangrenous adnexae followed by interval cystectomy: case report and review of the literature. Int J Reprod Contracept Obstet Gynecol 2015;4:898-901. 